\title{
Retinoid regulation of heparin-binding EGF- like growth factor gene expression in human keratinocytes and skin*
}

Stoll SW, Elder JT. Retinoid regulation of heparin-binding EGF-like growth factor gene expression in human keratinocytes and skin. Exp Dermatol 1998: 7: 391-397. (c) Munksgaard, 1998

Abstract: Retinoic acid (RA) has profound effects on epidermal homeostasis; however, the molecular mechanisms by which retinoids regulate keratinocyte cell proliferation and differentiation are not well understood. Here we report that mRNA expression of heparin-binding EGF-like growth factor (HB-EGF), a member of the EGF family of growth factors, is induced by RA in human keratinocytes and skin, and is overexpressed in the context of epidermal hyperplasia in vivo. Treatment of normal adult human keratinocytes with micromolar concentrations of RA significantly induced the expression of HB-EGF. The response was efficiently blocked by specific inhibitors of ErbB tyrosine kinase activity, MAP kinase kinase (MEK), or p38 stress-activated protein kinase. RA also enhanced the induction of HB-EGF mRNA in human skin organ culture, an ex vivo model system displaying many similarities to wound healing in vivo. HBEGF transcripts were markedly increased in human skin by topical treatment with RA under conditions known to provoke epidermal hyperplasia. HB-EGF transcripts were also markedly overexpressed in the hyperplastic epidermis of psoriatic lesions, relative to normal skin. These results support the hypothesis that the effects of RA on epidermal hyperplasia are mediated at least in part by HB-EGF, and suggest that signal transduction mechanisms other than or in addition to nuclear RA receptors contribute to this effect.

\author{
S. W. Stoll ${ }^{1}$ and J. T. Elder ${ }^{1,2}$ \\ Departments of ${ }^{1}$ Dermatology and ${ }^{2}$ Radiation \\ Oncology (Cancer Biology), University of \\ Michigan, Ann Arbor, Michigan, USA
}

Key words: heparin-binding EGF-like growth factor - retinoic acid - psoriasis - signal transduction - keratinocytes - gene expression

Dr Elder, 3312 CCGC, Cancer Center and Geriatrics Center Building, University of Michigan, Ann Arbor, MI 48109-0932, USA Tel.: (734) 763-0355. Fax: (734) 763-4575 e-mail jelder@umich.edu

Accepted for publication 2 April 1998

\section{Introduction}

Retinoids, the natural and synthetic metabolites and analogs of vitamin A (retinol), are important regulators of epidermal proliferation and differentiation (1). These compounds, among which alltrans retinoic acid (RA) is the major naturally occurring biologically active form, are thought to

\footnotetext{
Abbreviations:

EGF: epidermal growth factor; TGF- $\alpha$ : transforming growth factor- $\alpha$; HB-EGF: heparin-binding EGF-like growth factor; RA: retinoic acid; KBM: keratinocyte basal medium; KGM: keratinocyte growth medium; NHK: normal human keratino-
} cytes; RARE: retinoic acid response element.

* Parts of this work were presented at the annual meeting of the Society of Investigative Dermatology, Washington, DC, April 1996. mediate their effects by binding to nuclear receptors belonging to the steroid hormone receptor superfamily of ligand-inducible transcription factors (2). Two families of RA receptors have been identified, called retinoic acid receptors (RAR) and retinoid X receptors (RXR), and each family consists of 3 members expressed as a series of isotypes (3). Following ligand binding these transcription factors have been shown to form homo- and/or heterodimers: RARs heterodimerize with RXRs and bind to specific sequences called retinoic acid responsive elements (RARE), whereas RXRs can homodimerize or form heterodimers with several other members of the steroid receptor superfamily (4). RARE have been identified in the promoters of several genes including cellular retinoic acid binding protein II (CRABP-II), mouse and rat cellular retinol binding protein (CRBP) and the 


\section{Stoll \& Elder}

hyperproliferative keratin K6 (5-8). However, none of these genes have been shown to be directly responsible for the robust epidermal proliferation which occurs in response to topical retinoid treatment $(9,10)$.

In order to better understand the molecular mechanisms involved in retinoid regulation of epithelial proliferation, we tested whether heparinbinding EGF-like growth factor (HB-EGF), a member of the EGF-like growth factor family (11), is regulated by RA treatment of epidermal cells. Several members of this family, including transforming growth factor- $\alpha$ (TGF- $\alpha$ ) and amphiregulin (AR) in addition to HB-EGF, are expressed by keratinocytes in an autocrine fashion (12-14). Among these factors, HB-EGF is markedly overexpressed in wound healing (15-17) and AR is overexpressed in a variety of dermatoses characterized by epidermal hyperproliferation (18). However, we found that AR was expressed at much lower levels than was HB-EGF in actual healing skin wounds $(15,19)$. Here we report that HBEGF expression is markedly induced in response to retinoid treatment of cultured keratinocytes as well as in human skin in vivo and in organ culture. We also present inhibitor studies that implicate signal transduction mechanisms other than or in addition to ligand-dependent activation of nuclear receptors in the keratinocyte response to RA. Finally, we demonstrate for the first time the overexpression of HB-EGF in psoriatic lesions, which are characterized by marked epidermal hyperplasia.

\section{Materials and methods}

\section{Materials}

RA and the corticosteroid triamcinolone acetonide were purchased from Sigma (St Louis, MO, USA). The synthetic retinoids P-[(E)-2-(5,6,7,8-tetrahydro-5,5,8,8-tetramethyl-2-naphtalenyl)-1-propenyl] benzoic acid (TTNPB) and M-[(E)-2-(5,6,7,8-tetrahydro-5,5,8,8-tetramethyl-2-naphtalenyl)-1-propenyl] benzoic acid (meta-carboxy TTNPB, mcTTNPB) were supplied by Dr James Mezick of the R.W. Johnson Pharmaceutical Research Institute, Raritan, NJ, USA. The synthetic 1,25-dihydroxyvitamin $\mathrm{D}_{3}$ analogue MC903 (calcipotriol) was the generous gift of Dr Knud Kragballe, University of Aarhus, Aarhus, Denmark. The EGFR tyrosine kinase inhibitor PD153035 (20) was generously provided by Drs D. Fry and W. R. Leopold (Parke Davis Pharmaceutical Research, Ann Arbor, MI, USA), the MAP kinase kinase (MEK) inhibitor PD98059 (21) and the p38 stress-activated protein kinase inhibitor SB202190 were purchased from Calbiochem (La Jolla, CA, USA). Radiochemicals were purchased from Amersham Corp. (Arlington Heights, IL, USA).

\section{Cell culture}

Normal human keratinocytes (NHK, 2nd-4th passage) were grown in low calcium containing modified MCDB 153 medium (KGM, Clonetics, San Diego, CA, USA, or Medium 154, Cascade Biologics, Portland, OR, USA), as previously described (22). At either $20-30 \%$ confluence or $100 \%$ confluence, the cells were incubated with or without $3 \mathrm{nM}$ and $3 \mu \mathrm{M}$ RA for $48 \mathrm{~h}$ or with or without $3 \mu \mathrm{M}$ RA for 4 and $24 \mathrm{~h}$. For inhibitior studies, confluent cell monolayers were pretreated for $1 \mathrm{~h}$ with either PD153035 $(0.2 \mu \mathrm{M})$, PD98059 $(10 \mu \mathrm{M})$ or SB202190 $(3 \mu \mathrm{M})$, then treated with or without $3 \mu \mathrm{M}$ RA for various periods.

\section{Skin biopsies}

After obtaining informed consent, split-thickness skin biopsies $(0.2-0.4 \mathrm{~mm})$ were removed from the buttocks of psoriatic patients or healthy volunteers using a keratome as previously described (23). All procedures involving human subjects were approved by the Institutional Review Board of the University of Michigan. For studies involving in vivo retinoic acid treatment, RA powder was dissolved in $70 \%$ ethanol $/ 30 \%$ propylene glycol, applied once to the buttocks, and maintained under plastic wrap occlusion, as previously described (24). Controls were treated with ethanol/propylene vehicle under identical conditions. After 4 days of treatment, keratome biopsies were frozen immediately in liquid nitrogen prior to RNA extraction.

\section{Organ culture}

Keratome strips were cut into $2 \times 2 \mathrm{~cm}$ squares and frozen either immediately in liquid nitrogen or transported to the laboratory at room temperature in low-calcium, serum-free modified MCDB medium without added growth factors (KBM) (Keratinocyte Basal Medium, Clonetics; San Diego, CA, USA, or Medium 154, Cascade Biologics, Inc.; Portland, OR, USA) within 15 min. Upon arrival in the laboratory the tissue was placed, stratum corneum up, in $35 \mathrm{~mm}$ tissue culture dishes and incubated in $\mathrm{KBM}$ at $37^{\circ} \mathrm{C}$ in a $5 \% \mathrm{CO}_{2}$ incubator in the presence or absence of $3 \mu \mathrm{M} \mathrm{RA}, 3 \mu \mathrm{M}$ triamcinolone acetonide, $0.3 \mu \mathrm{M}$ TTNPB, $0.3 \mu \mathrm{M}$ mc-TTNPB, or $1 \mu \mathrm{M}$ MC903. After $24 \mathrm{~h}$ of incubation, the tissue samples were snap frozen in liquid nitrogen and processed for RNA isolation as described later. 


\section{RNA isolation and northern blotting}

Total RNA was isolated from cells and human skin keratome biopsies as previously described (15). Thirty to forty $\mu \mathrm{g}$ of RNA were separated on $1 \%$ formaldehyde agarose gels, blotted to nylon membranes (Zeta-Probe, Bio-Rad, Richmond, CA, USA) and hybridized against HB-EGF and 36B4 as previously described (15). Hybridization signals were visualized by autoradiography and/or quantitated by phosphorimager (Molecular Dynamics, Inc. Sunnyvale, CA, USA). Quantitated hybridization signals were normalized to the control gene $36 B 4$ and expressed as fold change relative to the values obtained for normal or untreated skin. Statistical analysis of the fold change values was performed using paired or unpaired Student $t$-tests, assuming unequal variances and a two-tailed hypothesis.

\section{Results}

Treatment of NHK with $3 \mu \mathrm{M}$ RA markedly and significantly increased HB-EGF mRNA expression compared to untreated control cultures at 24 and $48 \mathrm{~h}$, with a clear trend of induction at $4 \mathrm{~h}$ as well (Figs 1A and 1B). High concentrations of RA $(3 \mu \mathrm{M})$ inhibited the growth of subconfluent $\mathrm{KC}$ in this system (data not shown). However, the observed results could not be attributed to a reduction of HB-EGF inducibility in postconfluent $\mathrm{KC}$, as induction was comparable in confluent and subconfluent cells (Fig. 1B). Only very limited and non-significant induction of HB-EGF was observed in response to $3 \mathrm{nM}$ RA (Fig. 1B), a dose that induces marked induction of IL-1 $\beta$ mRNA in keratinocytes (25). Preincubation with $0.2 \mu \mathrm{M}$ of the EGFR tyrosine kinase inhibitor PD153035, 10

Figure 1. Retinoic acid increases HB-EGF mRNA expression in normal human keratinocytes. Total RNA was harvested and analyzed by quantitative northern blotting as described in Material and methods. (A) NHKs were grown in KGM to confluence and treated with $3 \mu \mathrm{M}$ RA for 4 and $24 \mathrm{~h}$. Asterisk $(*)$ denotes significant $(P<0.05)$ changes relative to untreated controls harvested after the same time intervals. (B) Normal human keratinocytes were grown to $30 \%$ or $100 \%$ confluence and incubated with or without $3 \mathrm{nM}$ or $3 \mu \mathrm{M}$ RA for $48 \mathrm{~h}$. The data shown in the bar graph are expressed relative to untreated controls harvested $48 \mathrm{~h}$ after reaching $30 \%$ confluence. (C) Confluent normal human keratinocyte cultures were pretreated with the EGFR tyrosine kinase inhibitor PD153035 $(0.2 \mu \mathrm{M})$, the MAP kinase kinase inhibitor PD98059 $(10 \mu \mathrm{M})$ or the p38 stress-activated protein kinase inhibitor SB202190 $(3 \mu \mathrm{M})$ for 1 $\mathrm{h}$, then incubated with or without $3 \mu \mathrm{M}$ RA for $4 \mathrm{~h}$, as indicated above the autoradiograms. Results obtained using keratinocytes from two different subjects are shown. Inhibitortreated keratinocytes showed no evidence of cytotoxicity by phase contrast microscopy (data not shown). $\mu \mathrm{M}$ of the MAP kinase kinase inhibitor PD98059 or $3 \mu \mathrm{M}$ of the p38 stress activated protein kinase inhibitor SB202190 for $1 \mathrm{~h}$ prior to RA treatment markedly reduced the induction of HB-EGF mRNA (Fig. 1C). In two experiments, we observed
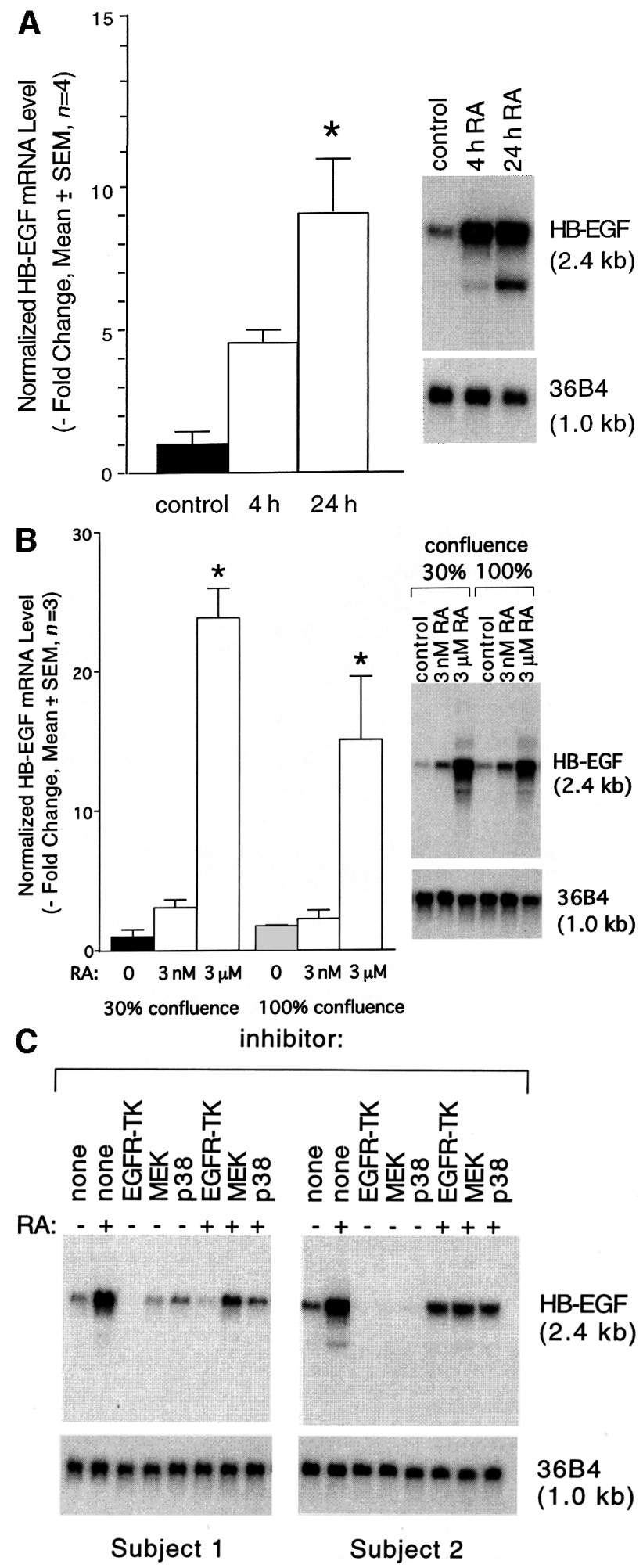


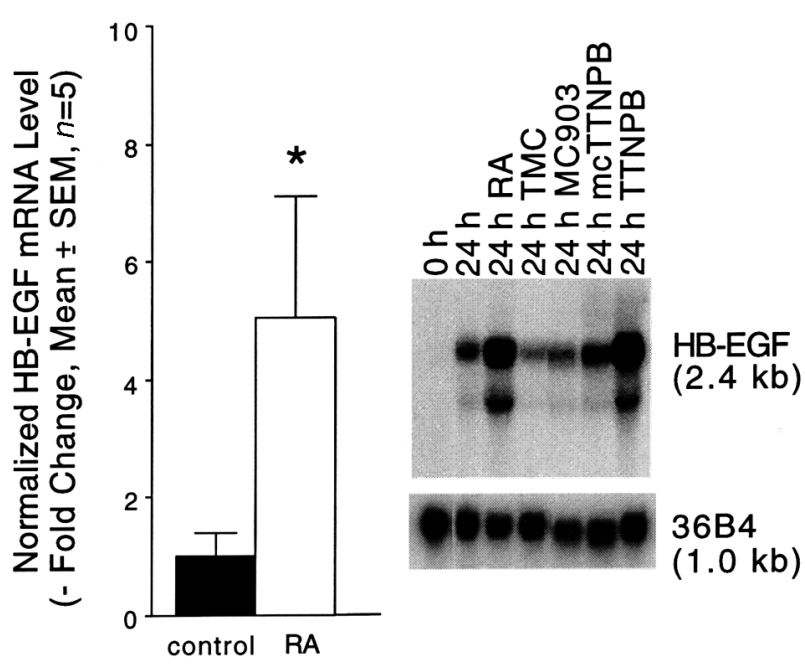

Figure 2. Retinoids potentiate HB-EGF gene expression in human skin organ culture. Keratome biopsy fragments were incubated in the presence or absence of $3 \mu \mathrm{M}$ RA, $3 \mu \mathrm{M}$ triamcinolone acetonide, $0.3 \mu \mathrm{M}$ TTNPB or mc-TTNPB, and $1 \mu \mathrm{M}$ MC903, as indicated above the autoradiograms. After $24 \mathrm{~h}$, total RNA was extracted and analyzed by quantitative northern blotting. Quantitative data are shown only for RA. Asterisk $(*)$ indicates significant $(P<0.05)$ differences between the responses obtained in RA-treated vs untreated skin organ cultured for the same length of time.

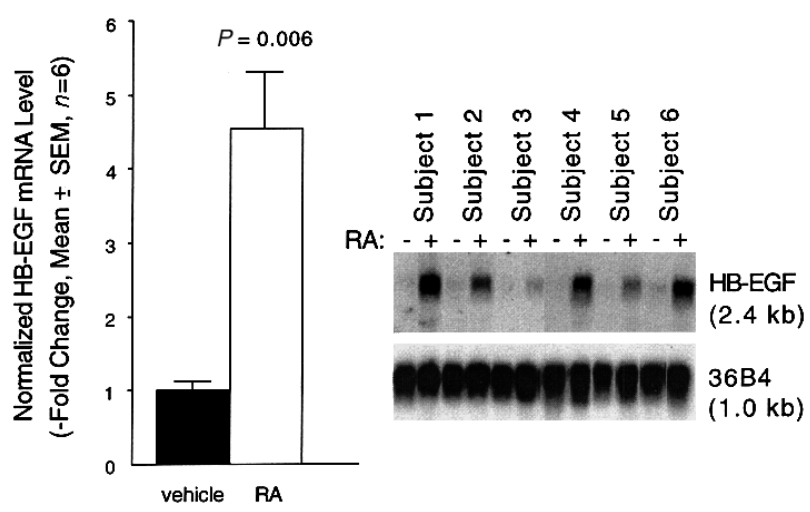

Figure 3. RA induces HB-EGF mRNA expression in normal human skin. Normal human skin was treated with $0.025 \%$ RA or vehicle under occlusion. Four days later, total RNA was harvested from keratome biopsies and analyzed by quantitative northern blotting. Results were quantitated as described in Materials and methods and expressed relative to vehicle treated skin.

1.1-, 2.2-, and 2.1-fold mean inductions for PD153035, PD98059 and SB202190 pretreated cultures, respectively, compared to a 4.9 -fold increase in response to RA treatment alone. Consistent with autocrine activation of keratinocytes via the EGFR (11), these agents also reduced HB-EGF mRNA levels in control cells not treated with RA (Fig. 1C). Results qualitatively similar to those shown in Figs $1 \mathrm{~A}-\mathrm{C}$ were obtained using the im- mortalized human keratinocyte cell line, HaCaT (data not shown).

The HB-EGF probe consistently hybridized to a minor, more rapidly migrating band corresponding to a transcript length of approximately $1.5 \mathrm{~kb}$. A similar band was observed in the original description of HB-EGF (26), and this "short form" of HB-EGF has recently been cloned and sequenced (27). We found no evidence for differential regulation of the full-length and "short-form" HB-EGF transcripts by RA.

Human skin organ culture provides an attractive in vitro model for dissecting the early events in wound healing (15). We have previously shown that HB-EGF mRNA is rapidly and markedly induced in this system, and that immunoreactive HB-EGF is formed (15). To evaluate the effects of RA on HB-EGF expression in this system, we incubated keratome fragments for $24 \mathrm{~h}$ in the presence of $3 \mu \mathrm{M}$ RA. As shown in Fig. 2, HB-EGF was significantly increased over and above the marked induction previously observed (15) in untreated organ cultures. The synthetic retinoid TTNPB also induced HB-EGF gene expression in this system, whereas its biologically inactive congener, mc-TTNPB (28), had no effect. Similarly, induction was not observed upon addition of high concentrations of the corticosteroid triamcinolone acetonide $(3 \mu \mathrm{M})$ or the Vitamin D analogue calcipotriol (MC903, $1 \mu \mathrm{M})$. In fact, at the concentration tested, both agents modestly reduced the induction of HB-EGF mRNA compared to DMSO-treated controls (Fig. 2).

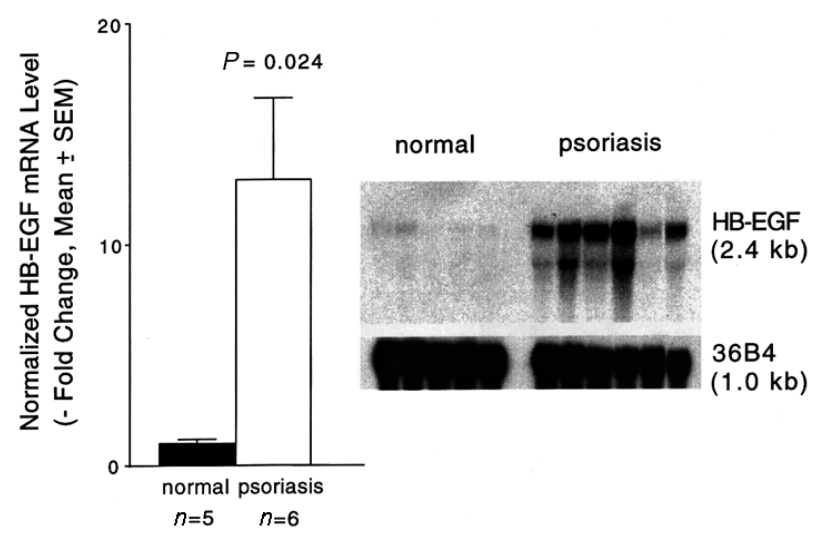

Figure 4. HB-EGF is overexpressed in lesional psoriatic skin. Total RNA was isolated from normal skin of 5 nondiseased individuals or chronic plaque lesions from 6 different psoriatic individuals and analyzed by quantitative northern blotting. The quantitative data are expressed as -fold inductions compared to normal skin. To accomplish this, the 36B4-normalized HBEGF band intensities for each individual were divided by the mean value obtained for the 5 normal skin controls. The insert shows autoradiograms of the corresponding northern blot sequentially hybridized against HB-EGF and 36B4. 
To determine if retinoids exert similar effects in vivo, human skin was treated under occlusion with $0.025 \%$ RA for 4 days, as previously described (29). As can be seen in Fig. 3, RA treatment markedly and significantly increased HB-EGF mRNA levels relative to vehicle controls in skin samples from 6 different individuals (4.5 \pm 0.8 -fold, $P=$ 0.006). No differences in HB-EGF expression were observed in vehicle-treated or occluded control samples, compared to untreated controls obtained from the same individuals (data not shown).

To assess the expression of HB-EGF in hyperplastic epidermis, we compared its expression in keratome biopsies of normal and lesional psoriatic skin. As shown in Fig. 4, HB-EGF transcripts were markedly induced, relative to the skin of normal volunteers $(12.9 \pm 3.7$-fold). There was substantial patient-to-patient variability in expression of these transcripts, as previously observed for TGF- $\alpha$ (30). Nevertheless, the comparison between normal and lesional skin was statistically significant ( $P=0.024$, by unpaired t-test).

\section{Discussion}

Although the hyperproliferative effects of retinoids on epithelial cells and skin in man and mice are well described $(9,10,31,32)$, RA-responsive genes that are directly involved in the regulation of epidermal growth are not yet well characterized. Here we show that HB-EGF, a heparin-binding member of the EGF family, is markedly induced in response to retinoid treatment in cultured keratinocytes, short-term organ cultures, and intact skin (Figs 1-3). In addition to numerous studies in cultured keratinocytes (reviewed in (11)), recent studies of transgenic mice overexpressing EGF receptor ligands as well as EGF receptor knockout mice strongly support a role for EGF receptor activation in keratinocyte hyperplasia in vivo (33-38). Induction of HB-EGF mRNA was observed not only in RA-treated skin and organ culture but also in RA-treated keratinocyte cultures, indicating that the response is autonomous to the keratinocyte and that dermal fibroblasts are not required. Our results therefore suggest that the effects of RA on epidermal hyperplasia may be mediated at least in part by keratinocyte-derived HB-EGF.

We consistently observed a lower molecular weight form of HB-EGF mRNA, as previously reported $(26,27)$. The size of this transcript is consistent with that of the recently-reported "short form" of HB-EGF, which has been shown to represent a probable alternatively-spliced transcript encoding the first two conserved disulfide loops of the EGF unit connected to a nine amino acid tail (27). We found no evidence for differential regulation of the long and short forms of HB-EGF by RA.

The marked inhibition of the keratinocyte HBEGF mRNA response by inhibitors of EGFR protein kinase, MAP kinase kinase, and p38 stressactivated protein kinase was unexpected. However, RA is known to exert several biological effects that are difficult to ascribe to nuclear receptor-mediated gene transcription (25). In support of this possibility, note that induction of HB-EGF was observed only at a pharmacologic $(3 \mu \mathrm{M})$ concentration of RA, whereas the keratinocyte IL-1 $\beta$ mRNA responses to RA can be observed at 0.3 $\mathrm{nM}$, a concentration close to the Kd for RA binding by purified RAR (25). Moreover, analysis of the published sequence of the HB-EGF promoter (39) did not reveal the presence of canonical retinoic acid response elements (RARE), as previously identified in the $5^{\prime}$ regulatory elements of other RA-responsive genes, including CRABP-II (5) and rat and mouse CRBP $(6,7)$. We could only identify one half-site, AGTTCA, 626 bp upstream of the major transcription start site. We cannot exclude the possibility that the observed half-site reflects a novel or variant RARE, or that elements consisting of two half sites may be present in an intron or upstream of the published HB-EGF DNA sequence. Nevertheless, these observations lead us to question whether the observed effects of RA on HB-EGF expression can be accounted for by ligand-dependent transcriptional activation of the HB-EGF gene. It remains possible that signal transduction initiated at the cell surface could merge with nuclear receptor signaling at the level of receptor phosphorylation (40).

The fact that HB-EGF is markedly overexpressed not only in healing wounds (15), but also in psoriatic lesions (Fig. 4) forges another link between psoriatic epidermal hyperplasia and wound healing (41). Previous studies have shown that application of RA before wounding enhanced healing $(42,43)$. It is possible that this beneficial effect could be due to enhanced expression of HB-EGF. Retinoids are quite effective for acute pustular psoriasis, but are less useful as a single agent in chronic plaque psoriasis because they induce prominent erythema and sensations of itching or burning when used at concentrations required to obtain an antipsoriatic effect (44). We have recently shown that induction of vascular permeability factor (VPF) is one of several responses to EGF receptor activation in organ-cultured skin (15). It is possible that induction of HB-EGF in response to pharmacologic concentrations of RA may induce VPF in chronic plaque lesions, producing unwanted erythema and irritation even as they carry out their "normalizing" effects on keratiniz- 


\section{Stoll \& Elder}

ation and other aspects of keratinocyte differentiation. If confirmed, our findings suggest that judicious combinations of nuclear-targeted retinoids and plasma membrane/cytoplasmic-targeted signal transduction inhibitors could significantly reduce the side effect of irritation that currently limits the efficacy of RA in psoriasis and other retinoid-responsive dermatoses.

\section{Acknowledgements}

We thank Dr James Mezick (R.W. Johnson Pharmaceutical Research Institute, Raritan, NJ, USA) for his generous provision of TTNPB and mc TTNPB. Calcipotriol (MC 903) was a generous gift of Dr Knud Kragballe (University of Aarhus, Aarhus, Denmark). We also thank Drs D. Fry and W.R. Leopold (Parke Davis Pharmaceutical Research, Ann Arbor, MI, USA) for generously providing PD153035. We would like to thank Carolyn Petersen and Suzan Rehbine for their invaluable assistance in obtaining keratome biopsies, and Ted Hamilton for statistical analysis. This work was supported by an award from the National Institute of Arthritis, Musculoskeletal and Skin Diseases (R29 AR 40016), by the Ann Arbor Veterans Administration Hospital, and by the Babcock Charitable Trust. SWS was the recipient of a Dermatology Foundation Research Fellowship.

\section{References}

1. Sporn M B, Roberts A B. Role of retinoids in differentiation and carcinogenesis. Cancer Res 1983: 43: 3034 3040 .

2. Mangelsdorf D J, Evans R M. The RXR heterodimers and orphan receptors. Cell 1995: 83: 841-850.

3. Fisher G J, Voorhees J J. Molecular mechanisms of retinoid actions in skin. FASEB J 1996: 10: 1002-1013.

4. Chambon P. A decade of molecular biology of retinoic acid receptors. FASEB J 1996: 10: 940-954.

5. Astrom A, Pettersson U, Chambon P, Voorhees J J. Retinoic acid induction of human cellular retinoic acid-binding protein-II gene transcription is mediated by retinoic acid receptor-retinoid $\mathrm{X}$ receptor heterodimers bound to one far upstream retinoic acid-responsive element with 5-base pair spacing. J Biol Chem 1994: 269: 22334-22339.

6. Husmann M, Hoffmann B, Stump D G, Chytil F, Pfahl $\mathrm{M}$. A retinoic acid response element from the rat CRBPI promoter is activated by an RAP/RXR heterodimer. Biochem Biophys Res Commun 1992: 187: 1558-1564.

7. Smith W C, Nakshatri H, Leroy P, Rees J, Chambon P. A retinoic acid response element is present in the mouse cellular retinol binding protein I (mCRBPI) promoter. EMBO J 1991: 10: 2223-2230.

8. Navarro J M, Casatorres J, Jorcano J L. Elements controlling the expression and induction of the skin hyperproliferation-associated keratin K6. J Biol Chem 1995: 270: 21362 21367.

9. Fisher G J, Esmann J, Griffiths C E et al. Cellular, immunologic and biochemical characterization of topical retinoic acid-treated human skin [published erratum appears in $\mathbf{J}$ Invest Dematol 1991: Jun 96(6): 814]. J Invest Dermatol 1991: 96: 699-707.

10. Kang S, Duell E A, Fisher G J et al. Application of retinol to human skin in vivo induces epidermal hyperplasia and cellular retinoid binding proteins characteristic of retinoic acid but without measurable retinoic acid levels or irritation. J Invest Dermatol 1995: 105: 549-556.
11. Elder J. Transforming growth factor-alpha and related growth factors. In: Luger T, Schwarz T, ed. Epidermal Growth Factors and Cytokines. New York: Marcel Dekker, Inc., 1994: 205-240.

12. Hashimoto K, Higashiyama S, Asada $\mathrm{H}$ et al. Heparinbinding epidermal growth factor-like growth factor is an autocrine growth factor for human keratinocytes. J Biol Chem 1994: 269: 20060-20066.

13. Coffey R J, Jr., Derynck R, Wilcox J N et al. Production and auto-induction of transforming growth factor-alpha in human keratinocytes. Nature 1987: 328: 817-820.

14. Cook P W, Mattox P A, Keeble W W et al. A heparin sulfate-regulated human keratinocyte autocrine factor is similar or identical to amphiregulin. Mol Cell Biol 1991: 11: $2547-2557$.

15. Stoll S, Garner W, Elder J. Heparin-binding ligands mediate autocrine EGF receptor activation in skin organ culture. J Clin Invest 1997: 100: 1271-1281.

16. McCarthy D W, Downing M T, Brigstock D R et al. Production of heparin-binding epidermal growth factor-like growth factor (HB-EGF) at sites of thermal injury in pediatric patients. J Invest Dermatol 1996: 106: 49-56.

17. Marikovsky M, Breuing K, Liu P Y et al. Appearance of heparin-binding EGF-like growth factor in wound fluid as a response to injury. Proc Natl Acad Sci U S A 1993: 90: 3889-3893.

18. Piepkorn M. Overexpression of amphiregulin, a major autocrine growth factor for cultured human keratinocytes, in hyperproliferative skin disease. Am J Dermatopathol 1996: 18: 165-171.

19. Stoll S W, Elder J T. Autoinductive EGF receptor activation is an important early event in cutaneous wound healing [abstract]. J Invest Dermatol 1996: 106: 820A.

20. Fry D W, Kraker A J, McMichael A et al. A specific inhibitor of the epidermal growth factor receptor tyrosine kinase. Science 1994: 265: 1093-1095.

21. Allessi D R, Cuenda A, Cohen P, Dudley D T, Saltiel A R. PD 098059 is a specific inhibitor of the activation of mitogen-activated protein kinase in vitro and in vivo. $\mathrm{J}$ Biol Chem 1995: 270: 27489-27494.

22. Elder J, Fisher G, Duell E, Kragbelle K, Voorhees J. Regulation of keratinocyte growth and differentiation: interactive signal transduction pathways. In: Goldsmith L, ed. Physiology, Biochemistry, and Molecular Biology of the skin. New York: Oxford University Press, 1991: 266-313.

23. Voorhees J J, Duell E A, Bass L J, Powell J A, Harrell E R. Decreased cyclic AMP in the epidermis of lesions of psoriasis. Arch Dermatol 1972: 105: 695-701.

24. Elder J T, Astrom A, Petterson U et al. Differential regulation of retinoic acid receptors and binding proteins in human skin. J Invest Dermatol 1992: 98: 673-679.

25. Elder J T, Fisher G J, Zhang Q Y et al. Retinoic acid receptor gene expression in human skin. J Invest Dermatol 1991: 96: 425-433.

26. Higashiyama S, Abraham J A, Miller J, Fiddes J C, Klagsbrun M. A heparin-binding growth factor secreted by macrophage-like cells that is related to EGF. Science 1991: 251: 936-939.

27. Loukianov E, Loukianova T, Wiedlocha A, Olsnes S. Expression of mRNA for a short form of heparin-binding EGF-like growth factor. Gene 1997: 195: 81-86.

28. Strickland S, Brietman F F, Frickel F, Nurrenbach A, Hadick E, Sporn M B. Structure-activity relationships of a new series of retinoidal enzoic acid derivatives as measured by induction of differentiation of murine F9 teratocarcinoma cells and human HL-60 promyclocystic leukemia cells. Cancer Res 1983: 43: 5268-5272.

29. Elder J T, Cromie M A, Griffiths C E, Chambon P, Voorhees J J. Stimulus-selective induction of CRABP-II mRNA: 
a marker for retinoic acid action in human skin. $\mathbf{J}$ Invest Dermatol 1993: 100: 356-359.

30. Elder J T, Fisher G J, Lindquist P B et al. Overexpression of transforming growth factor alpha in psoriatic epidermis. Science 1989: 243: 811-814.

31. Connor M J, Lowe N J. Induction of ornithine decarboxylase activity and DNA synthesis in hairless mouse epidermis by retinoids. Cancer Res 1983: 43: 5174-5177.

32. Lutzow-Holm C, De Angelis P, Clausen O P. Topical application of retinoic acid induces murine epidermal proliferation without reducing cell cycle time. A bivariate BrdUrd/ DNA flow cytometric study. Epithelial Cell Biol 1995: 4: 27 .

33. Vassar R, Fuchs E. Transgenic mice provide new insights into the role of TGF-alpha during epidermal development and differentiation. Genes Dev 1991: 5: 714-727.

34. Wang X J, Greenhalgh D A, Eckhardt J N, Rothnagel J A, Roop D R. Epidermal expression of transforming growth factor-alpha in transgenic mice: induction of spontaneous and 12-O-tetradecanoylphorbol-13-acetate-induced papillomas via a mechanism independent of Ha-ras activation or overexpression. Mol Carcinog 1994: 10: 15-22.

35. Cook P W, Piepkorn M, Clegg C $\mathrm{H}$ et al. Transgenic expression of the human amphiregulin gene induces a psoriasis-like phenotype. J Clin Invest 1997: 100: 22862294.

36. Miettinen P J, Berger J E, Meneses J et al. Epithelial immaturity and multiorgan failure in mice lacking epidermal growth factor receptor. Nature 1995: 376: 337-341.
37. Sibilia M, Wagner E F. Strain-dependent epithelial defects in mice laking the EGF receptor [published erratum appears in Science 1995 Aug 18: 269(5226): 909]. Science 1995: 269: 234-238.

38. Threadgill D W, Dlugosz A A, Hansen L A et al. Targeted disruption of mouse EGF receptor: effect of genetic background on mutant phenotype. Science 1995: 269: 230-234.

39. Fen Z, Dhadly M S, Yoshizumi M et al. Structural organization and chromosomal assignment of the gene encoding the human heparin-binding epidermal growth factor-like growth factor/diphtheria toxin receptor. Biochemistry 1993: 32: 7932-7938

40. Rochette-Egly C, Gaub M P, Lutz Y, Ali S, Scheuer I, Chambon P. Retinoic acid receptor-beta: immunodetection and phosphorylation on tyrosine residues. Mol Endocrinol 1992: 6: 2197-2209.

41. Mansbridge J N, Knapp A M. Changes in keratinocyte maturation during wound healing. J Invest Dermatol 1987: 89: 253-263.

42. Hung V C, Lee J Y, Zitelli J A, Hebda P A. Topical tretinoin and epithelial wound healing. Arch Dermatol 1989: 125: 65-69.

43. Popp C, Kligman A M, Stoudemayer T J. Pretreatment of photoaged forearm skin with topical tretinoin accelerates healing of full-thickness wounds. Br J Dermatol 1995: 132: $46-53$.

44. Greaves M W, Weinstein G D. Treatment of psoriasis [see comments]. N Engl J Med 1995: 332: 581-588. 